Research

Open Access

\title{
Effects of epinephrine and vasopressin on end-tidal carbon dioxide tension and mean arterial blood pressure in out-of-hospital cardiopulmonary resuscitation: an observational study
}

\author{
Stefan Mally, Alina Jelatancev and Stefek Grmec
}

Centre for Emergency Medicine Maribor, Ljubljanska 5, 2000 Maribor, Slovenia

Corresponding author: Stefan Mally, stefan.mally@triera.net

Received: 17 Oct 2006 Revisions requested: 22 Nov 2006 Revisions received: 28 Feb 2007 Accepted: 21 Mar 2007 Published: 21 Mar 2007

Critical Care 2007, 11:R39 (doi:10.1186/cc5726)

This article is online at: http://ccforum.com/content/11/2/R39

(c) 2007 Mally et al.; licensee BioMed Central Ltd.

This is an open access article distributed under the terms of the Creative Commons Attribution License (http://creativecommons.org/licenses/by/2.0), which permits unrestricted use, distribution, and reproduction in any medium, provided the original work is properly cited.

\begin{abstract}
Introduction Clinical data considering vasopressin as an equivalent option to epinephrine in cardiopulmonary resuscitation (CPR) are limited. The aim of this prehospital study was to assess whether the use of vasopressin during CPR contributes to higher end-tidal carbon dioxide and mean arterial blood pressure (MAP) levels and thus improves the survival rate and neurological outcome.

Methods Two treatment groups of resuscitated patients in cardiac arrest were compared: in the epinephrine group, patients received $1 \mathrm{mg}$ of epinephrine intravenously every three minutes only; in the vasopressin/epinephrine group, patients received 40 units of arginine vasopressin intravenously only or followed by $1 \mathrm{mg}$ of epinephrine every three minutes during CPR. Values of end-tidal carbon dioxide and MAP were recorded, and data were collected according to the Utstein style.
\end{abstract}

Results Five hundred and ninety-eight patients were included with no significant demographic or clinical differences between compared groups. Final end-tidal carbon dioxide values and average values of MAP in patients with restoration of pulse were significantly higher in the vasopressin/epinephrine group ( $p<$ 0.01 ). Initial (odds ratio [OR]: 18.65), average (OR: 2.86), and final (OR: 2.26) end-tidal carbon dioxide values as well as MAP at admission to the hospital (OR: 1.79) were associated with survival at 24 hours. Initial (OR: 1.61), average (OR: 1.47), and final (OR: 2.67) end-tidal carbon dioxide values as well as MAP (OR: 1.39) were associated with improved hospital discharge. In the vasopressin group, significantly more pulse restorations and a better rate of survival at 24 hours were observed $(p<$ 0.05). Subgroup analysis of patients with initial asystole revealed a higher hospital discharge rate when vasopressin was used $(p=0.04)$. Neurological outcome in discharged patients was better in the vasopressin group $(p=0.04)$.

Conclusion End-tidal carbon dioxide and MAP are strong prognostic factors for the outcome of out-of-hospital cardiac arrest. Resuscitated patients treated with vasopressin alone or followed by epinephrine have higher average and final end-tidal carbon dioxide values as well as a higher MAP on admission to the hospital than patients treated with epinephrine only. This combination vasopressor therapy improves restoration of spontaneous circulation, short-term survival, and neurological outcome. In the subgroup of patients with initial asystole, it improves the hospital discharge rate.

\section{Introduction}

Epinephrine (adrenaline) has been employed for cardiac resuscitation for more than a century, despite the knowledge that it can cause beta-mimetic complications [1-3]. Vaso- pressin is a potent vasopressor that could become a useful therapeutic alternative in the treatment of cardiac arrest because it has very little effect on pulmonary circulation and ventilation/perfusion mismatch [4-6]. Our previous study

ALS = advanced life support; $\mathrm{CPC}=$ cerebral performance category; $\mathrm{CPP}=$ coronary perfusion pressure; CPR = cardiopulmonary resuscitation; $\mathrm{MAP}=$ mean arterial blood pressure $; \mathrm{OHCA}=$ out-of-hospital cardiac arrest; pet $_{\mathrm{CO} 2}=$ end-tidal carbon dioxide tension; $\mathrm{ROSC}=$ restoration of spontaneous circulation. 
shows that vasopressin could become a better alternative to epinephrine [6]. Recent studies have shown that vasopressin is especially beneficial when combined with epinephrine during cardiopulmonary resuscitation (CPR) $[1,7]$.

Several studies show a strong correlation between end-tidal carbon dioxide tension (pet ${ }_{\mathrm{CO} 2}$ ) and cardiac output, coronary perfusion pressure (CPP) and cerebral perfusion pressure, restoration of spontaneous circulation (ROSC), and hospital discharge [8-13]. In addition, clinical studies were performed to demonstrate the correlation between mean arterial blood pressure (MAP) and survival as well as the neurological outcome after CPR [14,15].

The aim of this prehospital study was to compare the values of pet $_{\mathrm{CO} 2}$ and MAP in patients who suffered a cardiac arrest. They were divided in two groups; one was treated with epinephrine and the other with vasopressin. Our goal was to demonstrate that the use of vasopressin during CPR contributes to higher pet $\mathrm{CO}_{2}$ and MAP values and thus may have a beneficial impact on survival rate as well as on neurological outcome.

\section{Materials and methods}

In this observational prospective study in the town of Maribor, Slovenia (approximately 200,000 inhabitants), we collected data from January 2000 to April 2006 with the approval of the ethical review board of the Ministry of Health. All emergency calls in this period which were classified as out-of-hospital cardiac arrest (OHCA) in adults older than 18 years and which were dispatched to the prehospital emergency unit were included. In the Centre for Emergency Medicine Maribor, we have two prehospital emergency teams, which are advanced life support (ALS) units of three members with adequately equipped road vehicles (an emergency physician and two registered nurses or medical technicians). ALS was provided using a regional protocol that incorporates the standards and guidelines of the European Resuscitation Council (Antwerp, Belgium).

Exclusion criteria of the study were documented terminal illness, successful defibrillation without administration of a vasopressor, and severe hypothermia $\left(<30^{\circ} \mathrm{C}\right)$. We compared pet $_{\mathrm{CO} 2}$ and MAP in two treatment groups of resuscitated OHCA patients. In the epinephrine group, patients received 1 $\mathrm{mg}$ of epinephrine intravenously every three minutes. In the vasopressin/epinephrine group, patients received 40 units of arginine vasopressin (Pitressin; Goldshield Pharmaceuticals Ltd, Surrey, UK) intravenously only or followed by $1 \mathrm{mg}$ of epinephrine every three minutes during CPR. Patient allocation into these two groups depended on the year of incident (vasopressin has been the first therapy in ventricular fibrillation since November 2003 and in asystole since January 2005) and on accessibility of vasopressin in our prehospital unit (intermittently available since November 2000 and regularly available since November 2003). After successful resuscita- tion, patients were transferred to the intensive care unit of the Teaching Hospital Maribor.

Data were collected and analyzed according to the Utstein criteria. Demographic information, medical data, and pet $_{\mathrm{CO} 2}$ values were recorded for each patient by the emergency physician.

During resuscitation, the pet $_{\mathrm{CO} 2}$ values were measured and recorded every minute beginning with the initial postintubation pet $_{\mathrm{CO} 2}$ (first pet $\mathrm{CO}_{2}$ value obtained) and ending with the final pet $_{\mathrm{CO} 2}$ value at admission to the hospital. The initial MAP was the first measurement of MAP after ROSC, and the final MAP was recorded at admission to the hospital. Measurements of pet $_{\mathrm{CO} 2}$, arterial blood pressure, and other parameters were performed with a LIFEPACK 12 defibrillator monitor (PhysioControl, Inc., part of Medtronic, Inc., Minneapolis, MN, USA). Hospital records were used for outcome analysis, including assessment of cerebral performance category (CPC), for patients discharged alive.

Data were expressed as mean \pm standard deviation or as number (percentage). For analysis of variables, we used the Fisher exact test and the Wilcoxon rank sum test. The Bonferroni correction was applied for multiple comparisons. The null hypothesis was considered to be rejected at $p$ values of less than 0.05. Analyses of independent predictors for ROSC and survival from univariate analysis were performed using a multivariate logistic regression. For statistical analysis, we used SPSS software (version 12.01; SPSS Inc., Chicago, IL, USA).

\section{Results}

Out of 636 patients, 38 were excluded from the study because they were successfully defibrillated without administration of a vasopressor. Patients from the recent vasopressin study [6] (patients with initial ventricular fibrillation) were included in this study. There were no significant differences between demographic and initial clinical characteristics in the compared groups: first monitored rhythm, location of arrest, witnessed arrest, etiology of arrest, gender, age, time to initiation of CPR, and initial pet $\mathrm{CO}_{2}$ (Tables 1 to 3 ).

The initial, average, and final values of pet $_{\mathrm{CO}_{2}}$ were significantly higher in patients with ROSC on admission to the hospital compared with patients without ROSC in both groups $(p<$ 0.01). All patients with ROSC had an initial pet $\mathrm{CO}_{2}$ value greater than $1.33 \mathrm{kPa}$. The average pet $\mathrm{CO}_{2}$ values in patients with and without ROSC and the final pet $\mathrm{CO}_{2}$ values in patients with ROSC were significantly higher in the vasopressin/epinephrine group $(p<0.01)$. The average values of initial and final MAP were significantly higher in the vasopressin/epinephrine group $(p<0.01)$ (Table 3$)$.

In multivariate analysis, initial, average, and final pet $\mathrm{CO}_{2}$ values, initial MAP, and use of vasopressin were associated with 
Table 1

\begin{tabular}{|c|c|c|c|}
\hline CPR data & Epinephrine group & Vasopressin group & $p$ value $^{\mathrm{a}}$ \\
\hline Resuscitation attempts & $n=452$ & $n=146$ & \\
\hline \multicolumn{4}{|l|}{ First monitored rhythm } \\
\hline Shockable & $175 / 452(39 \%)$ & $70 / 146(48 \%)$ & 0.22 \\
\hline VF & $153 / 452(34 \%)$ & $62 / 146(42 \%)$ & \\
\hline VT & $22 / 452(5 \%)$ & $8 / 146(5 \%)$ & \\
\hline Non-shockable & $277 / 452(61 \%)$ & $76 / 146(52 \%)$ & 0.28 \\
\hline Asystole & $183 / 452(40 \%)$ & $44 / 146(30 \%)$ & \\
\hline PEA & $94 / 452(21 \%)$ & $32 / 146(22 \%)$ & \\
\hline \multicolumn{4}{|l|}{ Location of arrest } \\
\hline Home & $235 / 452(52 \%)$ & $76 / 146(52 \%)$ & 0.91 \\
\hline Public place & $172 / 452(38 \%)$ & $55 / 146(38 \%)$ & \\
\hline Other & $45 / 452(10 \%)$ & $15 / 146(10 \%)$ & \\
\hline \multicolumn{4}{|l|}{ Arrest witnessed } \\
\hline By lay persons & $277 / 452(61 \%)$ & $98 / 146(67 \%)$ & 0.67 \\
\hline By health care personnel & $40 / 452(9 \%)$ & $16 / 146(11 \%)$ & \\
\hline Arrest not witnessed & $135 / 452(30 \%)$ & $32 / 146(22 \%)$ & \\
\hline \multicolumn{4}{|l|}{ Etiology } \\
\hline Presumed cardiac & $307 / 452(68 \%)$ & $98 / 146(67 \%)$ & 0.69 \\
\hline Trauma & $10 / 452(2 \%)$ & $7 / 146(5 \%)$ & \\
\hline Submersion & $21 / 452(5 \%)$ & $7 / 146(5 \%)$ & \\
\hline Respiratory & $41 / 452(9 \%)$ & $15 / 146(10 \%)$ & \\
\hline Other non-cardiac & $36 / 452(8 \%)$ & $11 / 146(8 \%)$ & \\
\hline Unknown & $37 / 452(8 \%)$ & $8 / 146(6 \%)$ & \\
\hline \multicolumn{4}{|l|}{ Outcome (number) } \\
\hline Any ROSC & $262 / 452(58 \%)$ & $98 / 146(67 \%)$ & 0.04 \\
\hline $\begin{array}{l}\text { ROSC and admission to } \\
\text { hospital }\end{array}$ & $207 / 452(46 \%)$ & $91 / 146(62 \%)$ & 0.01 \\
\hline Survived 24 hours & $157 / 452(35 \%)$ & $75 / 146(51 \%)$ & 0.02 \\
\hline Discharged alive & $90 / 452(20 \%)$ & $36 / 146(25 \%)$ & 0.19 \\
\hline
\end{tabular}

aBy Fisher exact test. CPR, cardiopulmonary resuscitation; PEA, pulseless electrical activity; ROSC, restoration of spontaneous circulation; VF, ventricular fibrillation; VT, ventricular tachycardia without pulse.

ROSC and admission to the hospital (Table 4); initial, average, and final pet $\mathrm{CO}_{2}$ values, final MAP, and use of vasopressin were associated with survival at 24 hours (Table 5); initial, average, and final pet $\mathrm{CO}_{2}$ values and final MAP were associated with final survival and hospital discharge (Table 6). Vasopressin/epinephrine therapy was not associated with improved hospital discharge.

In outcome analysis, we found significantly higher rates of ROSC and survival at 24 hours in the vasopressin/epinephrine group $(p<0.05)$ (Table 1). There was no difference in survival to hospital discharge between groups $(p=0.19)$, but when analyzing the subgroup of patients in asystole, we found a significantly higher hospital discharge rate in patients treated with vasopressin (epinephrine subgroup 17/183 [9.3\%] versus vasopressin/epinephrine subgroup 10/44 [22.7\%]; $p=0.04$; Fisher exact test). In the epinephrine group, significantly higher doses of additional epinephrine were needed, CPR lasted longer, and significantly more patients needed additional atropine, bicarbonate, and inotropic agents than in the vasopressin/epinephrine group $(p<0.05)$. 
Table 2

Demographic and clinical characteristics of out-of-hospital cardiac arrest patients

\begin{tabular}{|c|c|c|}
\hline Characteristics & Epinephrine group $(n=452)$ & Vasopressin group $(n=146)$ \\
\hline Males/females ${ }^{a}$ & $301 / 151$ & $95 / 51$ \\
\hline Age in years ${ }^{b}$ & $62.2 \pm 17.8$ & $60.8 \pm 15.9$ \\
\hline Bystander CPR, number (percentage)a & $99 / 452(22 \%)$ & $31 / 146(21 \%)$ \\
\hline Time to initiation of CPR in minutes ${ }^{b}$ & $8.6 \pm 5.3$ & $7.8 \pm 5.1$ \\
\hline Average dose of epinephrine in milligrams $s^{b, c}$ & $7.6 \pm 4.2$ & $4.5 \pm 2.7$ \\
\hline Bicarbonate, number (percentage) ${ }^{a, c}$ & $172 / 452(38 \%)$ & $31 / 146(21 \%)$ \\
\hline Atropine, number (percentage) $)^{a, c}$ & $186 / 452(41 \%)$ & $42 / 146(29 \%)$ \\
\hline Dopamine, dobutamine, and norepinephrine, number (percentage) a,c $^{\mathrm{a}}$ & $98 / 452(22 \%)$ & $15 / 146(10 \%)$ \\
\hline Resuscitation by medical team in minutes ${ }^{b, c}$ & $29.3 \pm 9.4$ & $18.7 \pm 7.8$ \\
\hline
\end{tabular}

${ }^{a}$ By Fisher exact test; b by Wilcoxon rank sum test; ${ }^{c} p<0.05$. CPR, cardiopulmonary resuscitation.

Out of all cases of cardiac arrest, 90 patients in the epinephrine group and 36 in the vasopressin/epinephrine group were discharged alive from the hospital. Forty-seven discharged patients in the epinephrine group were with CPC-1 or CPC-2 (52\% of survivors), 37 patients with CPC-3 or CPC-4 (41\%), and 6 patients with CPC-5 (7\%). In the vasopressin/ epinephrine group, 26 discharged patients were with CPC-1 or CPC-2 (72\%), 8 patients with CPC-3 or CPC-4 (22\%), and 2 patients with CPC-5 (6\%). Neurological outcome of discharged patients was better (CPC-1 or CPC-2) in the vasopressin/epinephrine group ( $p=0.04)$.

\section{Discussion}

In previous studies, the relationship between pet $\mathrm{CO}_{2}$ and prognosis was established in prehospital CPR [11-13]. In this study, however, the main focus was on the relationship between pet $\mathrm{CO}_{2}$ and MAP and subsequent outcomes. The rel- evant hemodynamic parameters of resuscitated patients treated with epinephrine only and patients treated with vasopressin (only or in combination with epinephrine) were compared along with their prognostic value in CPR outcome.

The results of this study are similar to those of the studies of Wenzel and colleagues [4] and Guyette and colleagues [5] and show higher rates of ROSC and survival at 24 hours in the group of patients treated with vasopressin. In addition, this study shows that the patients who had asystole as the initial arrest rhythm and who were treated with vasopressin have a higher hospital discharge rate. The average and final pet $\mathrm{CO}_{2}$ values in vasopressin-treated patients with ROSC were significantly higher. The initial and the final MAP values were significantly higher in the vasopressin group as well. These results suggest that vasopressin could be more potent than epinephrine in increasing the cardiac output.

Table 3

End-tidal pressure of carbon dioxide and mean arterial blood pressure in two groups of cardiac arrest patients

\begin{tabular}{|c|c|c|c|}
\hline Variables & Epinephrine group & Vasopressin group & $p$ value $^{a}$ \\
\hline Median of pet $\mathrm{CO}_{2}$ reading & 16 & 15 & 0.86 \\
\hline Interquartile range & $5-26$ & $6-23$ & \\
\hline Average pet $\mathrm{CO} 2_{2}$ (patients with ROSC) & $2.12 \pm 0.51$ & $3.6 \pm 0.86$ & $<0.01$ \\
\hline Average pet $\mathrm{CO}_{\mathrm{C}}$ (patients without ROSC) & $0.92 \pm 0.28$ & $1.78 \pm 0.58$ & $<0.01$ \\
\hline Initial pet ${ }_{\mathrm{CO} 2}$ (patients with ROSC) & $2.24 \pm 0.81$ & $2.13 \pm 0.72$ & 0.87 \\
\hline Initial pet $_{\mathrm{CO} 2}$ (patients without ROSC) & $0.85 \pm 0.64$ & $1.05 \pm 0.64$ & 0.48 \\
\hline Final pet $_{\mathrm{CO} 2}$ (patients with ROSC) & $2.95 \pm 0.42$ & $4.68 \pm 1.1$ & $<0.01$ \\
\hline Final pet $_{\mathrm{CO} 2}$ (patients without ROSC) & $0.78 \pm 0.52$ & $0.88 \pm 0.38$ & 0.84 \\
\hline Average initial MAP & $74.6 \pm 11.3$ & $92.4 \pm 9.7$ & $<0.01$ \\
\hline Average final MAP & $80.3 \pm 12.4$ & $105.8 \pm 16.1$ & $<0.01$ \\
\hline
\end{tabular}

aBy Wilcoxon rank sum test. MAP, mean arterial blood pressure (in millimeters of mercury); pet $_{\mathrm{CO} 2}$, end-tidal pressure of carbon dioxide (in kilopascals); ROSC, restoration of spontaneous circulation. 
Table 4

\begin{tabular}{|c|c|c|c|}
\hline Variables & Odds ratio & $95 \%$ confidence interval & $p$ value \\
\hline Shockable rhythm (VF, VT) & 2.11 & $1.14-2.87$ & 0.016 \\
\hline Arrival time & $1.38^{\mathrm{a}}$ & $1.07-2.55$ & 0.008 \\
\hline Witnessed arrest & 1.27 & $0.76-1.94$ & 0.54 \\
\hline Bystander CPR & 2.43 & $1.21-4.98$ & 0.014 \\
\hline Initial pet $\mathrm{CO}_{2}{ }^{b}$ & 20.35 & $5.43-35.63$ & $<0.001$ \\
\hline Average pet $\mathrm{CO}_{2}{ }^{\mathrm{b}}$ & 6.36 & $2.30-8.34$ & $<0.001$ \\
\hline Final pet $\mathrm{CO}_{2}{ }^{b}$ & 2.85 & $1.43-3.92$ & 0.003 \\
\hline Initial MAPb & 1.25 & $1.13-1.86$ & 0.02 \\
\hline Vasopressin & 1.63 & $1.24-2.14$ & 0.012 \\
\hline Gender (female) & 2.85 & $1.36-5.48$ & 0.002 \\
\hline Period $2^{c}$ & 1.28 & $1.15-1.92$ & 0.02 \\
\hline
\end{tabular}

aValue proportional to each one-minute decrease in arrival time; bValues proportional to each increase by $1.33 \mathrm{kPa}$ (10 mm $\mathrm{Hg}$ ); ${ }^{\circ} \mathrm{CPR}$ performed in the period from November 2003 to April 2006 (period 1: January 2000 to November 2003). CPR, cardiopulmonary resuscitation; MAP, mean arterial blood pressure; pet $_{\mathrm{CO} 2}$, end-tidal pressure of carbon dioxide; VF, ventricular fibrillation; VT, ventricular tachycardia without pulse.

Using an animal model, Isserles and Breen [16] established a linear relationship between changes in pet $_{\mathrm{CO} 2}$ and cardiac output. The authors claim that, during a decreased cardiac output, reduced carbon dioxide delivery to the lung decreases alveolar carbon dioxide pressure and thus causes part of the decrease in pet $_{\mathrm{CO} 2}$. The remaining reduction in pet $\mathrm{CO} 2_{2}$ results from the increase in alveolar dead space due to the lower pulmonary perfusion pressure (dilution of carbon dioxide from perfused alveolar spaces). Gazmuri and colleagues [17,18] confirmed that both pet $\mathrm{CO}_{2}$ and $\mathrm{Pa}_{\mathrm{CO} 2}$ (arterial partial pressure of carbon dioxide) correspond with the pulmonary blood flow and therefore with cardiac output generated by precordial compressions during CPR.

In an animal study, Yannopoulos and colleagues [19] demonstrated a linear correlation between MAP, cerebral perfusion pressure and $\mathrm{CPP}$, and pet $_{\mathrm{CO} 2}$. A strong correlation between MAP and neurological outcome was observed in a few other studies [20-22]. In a study using a pig model of ventricular fibrillation cardiac arrest, Lindner and colleagues [23] concluded that administration of vasopressin led to a significantly higher CPP, myocardial blood flow, and total cerebral flow during CPR. In a study conducted by Morris and colleagues [24] using a human model of prolonged cardiac arrest, $40 \%$ of the patients receiving vasopressin had a significant increase in CPP. Our study shows that higher values of pet ${ }_{\mathrm{CO} 2}$ and MAP in patients treated with vasopressin are consistent with the better outcomes in the vasopressin group. In a multivariate analysis, we determined that the chances for survival are improved in patients with a higher MAP on admission to the hospital (for every 1.33-kPa increase in MAP, the chances for survival were 1.4 times better). We also determined that the chances for ROSC, survival at 24 hours, and hospital dis- charge are associated with the year in which CPR was administered (Tables 4 to 6). Various factors may cause differences between the two observed time periods. These include implementation of new CPR guidelines, renewal of dispatch protocols, application of vasopressin as first therapy, and improved phone communication.

In our study, we had significantly more patients with CPC-1 and CPC-2 in the vasopressin group than in the epinephrine group. In the postresuscitation period, MAP is usually kept at a normal level ( 80 to $100 \mathrm{~mm} \mathrm{Hg}$ ) or at least at a level that secures coronary perfusion (that is, $65 \mathrm{~mm} \mathrm{Hg}$ ). Results from the study by Bell and colleagues [25] indicate that, to secure cerebral perfusion and prevent secondary cerebral injury, MAP should be kept at a level higher than commonly accepted. In our study, vasopressin contributed to a higher average final MAP (approximately $105 \mathrm{~mm} \mathrm{Hg}$ ), thus preserving cerebral perfusion in the critical postresuscitation period of absent cerebral autoregulation.

Several investigations have demonstrated that vasopressin could improve hemodynamic variables in advanced vasodilatatory or hemorrhagic shock [26-32]. The study by Friesenecker and colleagues [27] showed that, under normal physiological conditions, vasopressin exerted significantly stronger vasoconstriction on large arterioles than norepinephrine. This observation could explain, in part, why vasopressin can be effective in advanced shock that is unresponsive to increases of catecholamines in the standard shock therapy.

In the epinephrine group, resuscitation efforts lasted longer and a significantly higher quantity of additional epinephrine was needed. Adrenergic stimulation by additional doses of 
Critical Care Vol 11 No 2 Mally et al.

Table 5

\begin{tabular}{|c|c|c|c|}
\hline Variables & Odds ratio & $95 \%$ confidence interval & $p$ value \\
\hline Shockable rhythm (VF, VT) & 1.27 & $1.08-1.58$ & 0.02 \\
\hline Arrival time & $1.32^{\mathrm{a}}$ & $1.24-1.68$ & 0.01 \\
\hline Witnessed arrest & 7.64 & $2.32-22.42$ & $<0.001$ \\
\hline Bystander CPR & 4.84 & $2.10-10.48$ & $<0.001$ \\
\hline Initial pet ${ }_{\mathrm{CO} 2}{ }^{b}$ & 18.65 & $6.14-32.27$ & $<0.001$ \\
\hline Average $\operatorname{pet}_{\mathrm{CO} 2}{ }^{b}$ & 2.86 & $1.42-4.65$ & $<0.001$ \\
\hline Final pet $\mathrm{CO} 2^{b}$ & 2.26 & $1.21-4.13$ & 0.012 \\
\hline Initial MAPb & 1.06 & $0.82-1.43$ & 0.46 \\
\hline Final MAPb & 1.79 & $1.28-3.12$ & 0.009 \\
\hline Vasopressin & 1.34 & $1.14-1.94$ & 0.024 \\
\hline Period $2^{c}$ & 1.68 & $1.20-2.94$ & 0.008 \\
\hline
\end{tabular}

aValue proportional to each one-minute decrease in arrival time; bValues proportional to each increase by $1.33 \mathrm{kPa}(10 \mathrm{~mm} \mathrm{Hg})$; ${ }^{\mathrm{C}} \mathrm{CPR}$ performed in the period from November 2003 to April 2006 (period 1: January 2000 to November 2003). CPR, cardiopulmonary resuscitation; MAP, mean arterial blood pressure; pet $\mathrm{CO}_{\mathrm{C}}$, end-tidal pressure of carbon dioxide.

epinephrine is associated with adverse cardiac effects, including postresuscitation myocardial dysfunction and increased myocardial oxygen consumption. That is one of the reasons why significantly larger doses of additional therapy (inotropes, vasopressors, atropine, and bicarbonate) were needed in the epinephrine group in comparison with the vasopressin group.

Increased doses of epinephrine have a direct impact on lowering the pet ${ }_{\mathrm{CO} 2}$ value [33]. Tang and colleagues [34] in an experimental model and Cantineau and colleagues [35] in a prospective human study established that epinephrine induces pulmonary ventilation/perfusion defects as a result of redistribution of pulmonary blood flow. Other studies show that high doses of epinephrine significantly decrease cardiac output and pet $_{\mathrm{CO}_{2}}$ but enhance myocardial perfusion pressure and myocardial blood flow [36,37]. Lindberg and colleagues [38] confirmed that an injection of epinephrine during chest compressions decreased pet $\mathrm{CO}_{2}$ and pulmonary blood flow and increased CPP (which then slowly decreased), but the effects on pet $\mathrm{CO}_{2}$ and pulmonary blood flow were prolonged. Therefore, epinephrine initially increases CPP and the chances of ROSC, but decreases pet $\mathrm{CO}_{2}$ value induced by

Table 6

\section{Variables associated with hospital discharge}

\begin{tabular}{|c|c|c|c|}
\hline Variables & Odds ratio & $95 \%$ confidence interval & $p$ value \\
\hline Shockable rhythm (VF, VT) & 1.34 & $1.22-1.92$ & 0.03 \\
\hline Arrival time & $1.46^{a}$ & $1.26-2.12$ & 0.01 \\
\hline Witnessed arrest & 6.84 & $2.27-20.67$ & $<0.001$ \\
\hline Bystander CPR & 4.45 & $1.98-9.48$ & $<0.001$ \\
\hline Initial pet $\mathrm{CO}_{2}{ }^{b}$ & 1.61 & $1.28-2.64$ & 0.008 \\
\hline Average pet $_{\mathrm{CO} 2}{ }^{b}$ & 1.47 & $1.22-1.93$ & 0.014 \\
\hline Final pet $\mathrm{CO}^{b}$ & 2.67 & $1.83-3.68$ & $<0.001$ \\
\hline Initial MAPb & 1.02 & $0.91-1.32$ & 0.54 \\
\hline Final MAPb & 1.39 & $1.23-2.13$ & 0.01 \\
\hline Vasopressin & 1.12 & $0.82-1.33$ & 0.42 \\
\hline Period $2^{c}$ & 1.32 & $1.19-1.95$ & 0.03 \\
\hline
\end{tabular}

aValue proportional to each one-minute decrease in arrival time; bValues proportional to each increase by $1.33 \mathrm{kPa}(10 \mathrm{~mm} \mathrm{Hg})$; ${ }^{\circ} \mathrm{CPR}$ performed in the period from November 2003 to April 2006 (period 1: January 2000 to November 2003). CPR, cardiopulmonary resuscitation; MAP, mean arterial blood pressure; pet ${ }_{\mathrm{CO} 2}$, end-tidal pressure of carbon dioxide. 
critical deterioration in cardiac output and thereby diminishes oxygen delivery.

Tang and colleagues [39] confirmed that the beta-adrenergic action of epinephrine has a detrimental effect on postresuscitation myocardial function because it increases myocardial oxygen consumption and decreases postresuscitation survival. In the study by Pan and colleagues [40], CPP was increased after vasopressin application and a significant positive correlation between pet $\mathrm{CO}_{2}$ and CPP was observed, suggesting that vasopressin has very little effect on pulmonary circulation and ventilation/perfusion mismatch.

Unlike vasopressin, epinephrine during CPR can, to some extent, reduce pet $\mathrm{CO}_{2}$ values because of its impact on the pulmonary circulation. Nevertheless, the values of pet $_{\mathrm{CO} 2}$, together with MAP, reliably reflect changes in cardiac output.

\section{Conclusion}

$\mathrm{Pet}_{\mathrm{CO} 2}$ and MAP values are prognostic factors for the outcome of OHCA. During a cardiac arrest, pet $_{\mathrm{CO} 2}$ can be considered an indirect parameter for the evaluation of cardiac output in prehospital monitoring together with MAP, when spontaneous circulation is restored. Patients treated with vasopressin alone or followed by epinephrine during CPR have higher average and final pet $\mathrm{CO}_{2}$ values as well as higher initial and final MAP values on admission to the hospital than patients treated with epinephrine only. The combination of vasopressor therapy (vasopressin followed by epinephrine) in CPR improves ROSC as well as short-term survival and neurological outcome. In the subgroup of patients with asystole as the initial rhythm, it improves the hospital discharge rate. Our findings suggest that the current guidelines for resuscitation established by the European Resuscitation Council, in which vasopressin is not considered even as a secondary alternative to epinephrine, should be revised.

\section{Key messages}

- During CPR, higher pet $\mathrm{CO}_{2}$ and MAP values were observed when vasopressin was used.

- Pet $_{\mathrm{CO} 2}$ and MAP are strong prognostic factors for the outcome of cardiac arrest.

- Compared to epinephrine, vasopressin in CPR improves ROSC as well as short-term survival and neurological outcome.

\section{Competing interests}

The authors declare that they have no competing interests.

\section{Authors' contributions}

SM participated in conceiving and designing the study and drafted the manuscript. AJ participated in collecting data and helped to draft the manuscript. SG performed the statistical analysis and made critical revisions of the study. All authors have read and approved the final manuscript.

\section{References}

1. Wenzel V, Lindner KH: Vasopressin combined with epinephrine during cardiac resuscitation: a solution for the future? Crit Care 2006, 10:125.

2. Ditchey RV, Lindenfeld J: Failure of epinephrine to improve the balance between myocardial oxygen supply and demand during closed-chest resuscitation in dogs. Circulation 1988, 78:382-389.

3. Paradis NA, Wenzel V, Southall J: Pressor drugs in the treatment of cardiac arrest. Cardiol Clin 2002, 20:61-78.

4. Wenzel V, Krismer AC, Arntz HR, Sitter H, Stadlbauer KH, Lindner $\mathrm{KH}$ : A comparison of vasopressin and epinephrine for out-ofhospital cardiopulmonary resuscitation. N Engl J Med 2004, 350:105-113.

5. Guyette FX, Guimond GE, Hostler D, Callaway CW: Vasopressin administered with epinephrine is associated with a return of a pulse in out-of-hospital cardiac arrest. Resuscitation 2004, 63:277-282.

6. Grmec S, Mally S: Vasopressin improves outcome in out-ofhospital cardiopulmonary resuscitation of ventricular fibrillation and pulseless ventricular tachycardia: a observational cohort study. Crit Care 2006, 10:R13.

7. Krismer AC, Wenzel V, Stadlbauer KH, Mayr VD, Lienhart HG, Arntz HR, Lindner $\mathrm{KH}$ : Vasopressin during cardiopulmonary resuscitation: a progress report. Crit Care Med 2004, 32:S432-435.

8. Lewis LM, Stothert J, Standeven J, Chandel B, Kurtz M, Fortney J: Correlation of end-tidal $\mathrm{CO}_{2}$ to cerebral perfusion during $\mathrm{CPR}$. Ann Emerg Med 1992, 21:1131-1134.

9. Idris AH, Staples ED, O'Brien DJ, Melker RJ, Rush WJ, Del Duca $\mathrm{KD}$, Falk JL: End-tidal carbon dioxide during extremely low cardiac output. Ann Emerg Med 1994, 23:568-572.

10. Shibutani K, Muraoka M, Shirasaki S, Kubal K, Sanchala VT, Gupte $\mathrm{P}$ : Do changes in end-tidal $\mathrm{PCO}_{2}$ quantitatively reflect changes in cardiac output? Anesth Analg 1994, 79:829-833.

11. Grmec S, Lah K, Tusek-Bunc K: Difference in end-tidal $\mathrm{CO}_{2}$ between asphyxia cardiac arrest and ventricular fibrillation/ pulseless ventricular tachycardia cardiac arrest in the prehospital setting. Crit Care 2003, 7:R139-144.

12. Grmec S, Kupnik D: Does the Mainz Emergency Evaluation Scoring (MEES) in combination with capnometry (MEESc) help in the prognosis of outcome from cardiopulmonary resuscitation in a prehospital setting? Resuscitation 2003, 58:89-96.

13. Salen $P, O^{\prime}$ Connor R, Sierzenski $P$, Passarello B, Pancu D, Melanson S, Arcona S, Reed J, Heller M: Can cardiac sonography and capnography be used independently and in combination to predict resuscitation outcomes? Acad Emerg Med 2001, 8:610-615.

14. Müllner M, Sterz F, Binder M, Hellwagner K, Meron G, Herkner H, Laggner AN: Arterial blood pressure after human cardiac arrest and neurological recovery. Stroke 1996, 27:59-62.

15. Sundgreen C, Larsen FS, Herzog TM, Knudsen GM, Boesgaard S, Aldershvile J: Autoregulation of cerebral blood flow in patients resuscitated from cardiac arrest. Stroke 2001, 32:128-132.

16. Isserles $\mathrm{SA}, \mathrm{Breen} \mathrm{PH}$ : Can changes in end-tidal $\mathrm{PCO}_{2}$ measure changes in cardiac output? Anesth Analg 1991, 73:808-814.

17. Gazmuri RJ, von Planta M, Weil MH, Rackow EC: Arterial $\mathbf{P C O}_{2}$ as an indicator of systemic perfusion during cardiopulmonary resuscitation. Crit Care Med 1989, 17:237-240.

18. Gazmuri RJ, Weil MH, Bisera J, Rackow EC: End-tidal carbon dioxide tension as a monitor of native blood flow during resuscitation by extracorporeal circulation. $J$ Thorac Cardiovasc Surg 1991, 101:984-988.

19. Yannopoulos D, Aufderheide TP, McKnite S, Kotsifas K, Charris R, Nadkarni V, Lurie KG: Hemodynamic and respiratory effects of negative tracheal pressure during CPR in pigs. Resuscitation 2006, 69:487-494.

20. Ornato JP, Levine RL, Young DS, Racht EM, Garnett AR, Gonzalez ER: The effect of applied chest compression force on systemic arterial pressure and end-tidal carbon dioxide concentration 
during CPR in human beings. Ann Emerg Med 1989, 18:732-737.

21. Li G, Tang N, DiScala C, Meisel Z, Levick N, Kelen GD: Cardiopulmonary resuscitation in pediatric trauma patients: survival and functional outcome. J Trauma 1999, 47:1-7.

22. Engdahl J, Abrahamsson P, Bang A, Lindqvist J, Karlsson T, Herlitz $\mathrm{J}$ : Is hospital care of major importance for outcome after outof-hospital cardiac arrest? Experience acquired from patients with out-of-hospital cardiac arrest resuscitated by the same Emergency Medical Service and admitted to one of two hospitals over a 16-year period in the municipality of Göteborg. Resuscitation 2000, 43:201-211.

23. Lindner $\mathrm{KH}$, Prengel AW, Pfenninger EG, Lindner IM, Strohmenger HU, Georgieff M, Lurie KG: Vasopressin improves vital organ blood flow during closed-chest cardiopulmonary resuscitation in pigs. Circulation 1995, 91:215-221.

24. Morris DC, Dereczyk BE, Grzybowski M, Martin GB, Rivers EP, Wortsman J, Amico JA: Vasopressin can increase coronary perfusion pressure during human cardiopulmonary resuscitation. Acad Emerg Med 1997, 4:878-883.

25. Bell DD, Brindley PG, Forrest D, Al Muslim O, Zygun D: Management following resuscitation from cardiac arrest: recommendations from the 2003 Rocky Mountain Critical Care Conference. Can J Anaesth 2005, 52:309-322.

26. Luckner G, Dünser MW, Jochberger S, Mayr VD, Wenzel V, Ulmer $\mathrm{H}$, Schmid S, Knotzer H, Pajk W, Hasibeder W, et al.: Arginine vasopressin in $\mathbf{3 1 6}$ patients with advanced vasodilatory shock. Crit Care Med 2005, 33:2659-2666.

27. Friesenecker BE, Tsai AG, Martini J, Ulmer H, Wenzel V, Hasibeder WR, Intaglietta M, Dünser MW: Arteriolar vasoconstrictive response: comparing the effects of arginine vasopressin and norepinephrine. Crit Care 2006, 10:R75.

28. Raedler C, Voelckel WG, Wenzel V, Krismer AC, Schmittinger CA, Herff H, Mayr VD, Stadlbauer KH, Lindner KH, Königsrainer A: Treatment of uncontrolled hemorrhagic shock after liver trauma: fatal effects of fluid resuscitation versus improved outcome after vasopressin. Anesth Analg 2004, 98:1759-1766.

29. Krismer AC, Wenzel $V$, Voelckel WG, Innerhofer $P$, Stadlbauer $K H$, Haas T, Pavlic M, Sparr HJ, Lindner KH, Königsrainer A: Employing vasopressin as an adjunct vasopressor in uncontrolled traumatic hemorrhagic shock. Three cases and a brief analysis of the literature. Anaesthesist 2005, 54:220-224.

30. Tsuneyoshi I, Onomoto M, Yonetani A, Kanmura Y: Low-dose vasopressin infusion in patients with severe vasodilatory hypotension after prolonged hemorrhage during general anesthesia. J Anesth 2005, 19:170-173.

31. Grmec S, Cander D, Strnad M, Vidovic D: Does vasopressin improve the outcome in traumatic out-of-hospital cardiac arrest from pulseless electrical activity (TOOHCA-PEA)? Crit Care Med 2005, 33:A127. (abstract)

32. Krismer AC, Dünser MW, Lindner KH, Stadlbauer KH, Mayr VD, Lienhart HG, Arntz RH, Wenzel V: Vasopressin during cardiopulmonary resuscitation and different shock states: a review of the literature. Am J Cardiovasc Drugs 2006, 6:51-68.

33. Martin GB, Gentile NT, Paradis NA, Moeggenberg J, Appleton TJ, Nowak RM: Effect of epinephrine on end-tidal carbon dioxide monitoring during CPR. Ann Emerg Med 1990, 19:396-398.

34. Tang W, Weil MH, Gazmuri RJ, Sun S, Duggal C, Bisera J: Pulmonary ventilation/perfusion defects induced by epinephrine during cardiopulmonary resuscitation. Circulation 1991, 84:2101-2107.

35. Cantineau JP, Merckx P, Lambert $Y$, Sorkine M, Bertrand C, Duvaldestin P: Effect of epinephrine on end-tidal carbon dioxide pressure during prehospital cardiopulmonary resuscitation. Am J Emerg Med 1994, 12:267-270.

36. Rivers EP, Wortsman J, Rady MY, Blake HC, McGeorge FT, Buderer NM: The effect of the total cumulative epinephrine dose administered during human CPR on hemodynamic, oxygen transport, and utilization variables in the postresuscitation period. Chest 1994, 106:1499-1507.

37. Chase PB, Kern KB, Sanders AB, Otto CW, Ewy GA: Effects of graded doses of epinephrine on both noninvasive and invasive measures of myocardial perfusion and blood flow during cardiopulmonary resuscitation. Crit Care Med 1993, 21:413-419.

38. Lindberg L, Liao $\mathrm{Q}$, Steen S: The effects of epinephrine/norepinephrine on end-tidal carbon dioxide concentration, coro- nary perfusion pressure and pulmonary arterial blood flow during cardiopulmonary resuscitation. Resuscitation 2000, 43:129-140.

39. Tang W, Weil MH, Sun S, Noc M, Yang L, Gazmuri RJ: Epinephrine increases the severity of postresuscitation myocardial dysfunction. Circulation 1995, 92:3089-3093.

40. Pan T, Zhou S, Studer W, von Planta M, Scheidegger D: Effect of different drugs on end-tidal carbon dioxide during rodent CPR. J Tongji Med Univ 1997, 17:244-246. 